\title{
An improved surveillance measure for adolescent smoking?
}

\author{
John P Pierce, Arthur J Farkas, Nicola Evans, Elizabeth Gilpin
}

\begin{abstract}
Objective-To assess the possible usefulness and validity of a new measure to identify adolescents at risk of smoking cigarettes.

Design - The new measure was compared with standard ones with respect to their ability to identify young adolescents at risk of later smoking cigarettes; and the correlation between known risk factors for smoking and both the new and the standard measure of current smoking was assessed.
\end{abstract}

Setting and subjects-Cross-sectional, population-based 1992 California Tobacco Survey of 1789 adolescents (1217 years) and 1667 adults (18-28 years). Main outcome measures - Susceptibility to smoke, defined as the absence of a firm resolve not to smoke; current smoking, defined as any smoking in the last month; and daily smoking.

Results-Less than $2 \%$ of 12 to 13 year olds reported current smoking, whereas $27 \%$ were susceptible. None reported daily smoking. Susceptibility rates peaked at around $45 \%$ at age 19 years, and peak rates of young adult daily smoking approached $25 \%$. Factors related to current smoking in logistic regression analysis were also related to susceptibility to smoke even among adolescents who had never smoked a whole cigarette, suggesting that susceptibility is indeed the first stage of smoking uptake.

Conclusion-Although it overestimates eventual adult smoking, the susceptibility measure should capture a greater percentage of young adolescents who eventually smoke than the current smoker measure. Subject to further validation in longitudinal studies, this measure may offer a means of focusing intervention resources on those adolescents at risk of starting to smoke. Also, this measure could be used for surveillance and as an outcome measure to assess the effectiveness of prevention programmes.

(Tobacco Control 1995; 4 (suppl 1): S47-S56) Keywords: adolescent smoking; smoking uptake; smoking prevalence

\section{Introduction}

Since the first evidence that smoking causes lung cancer was published, smoking initiation among adults has declined dramatically; by the mid-1980s few non-smokers started to smoke in adulthood. ${ }^{1}$ However, the public health campaign to reduce smoking prevalence appears to have had little impact on adolescents, an estimated 3000 of whom start to smoke each day. ${ }^{2}$ That it is possible to prevent smoking uptake is shown both by the adult data and by the virtual elimination of smoking uptake among medical students in the United States. ${ }^{3}$ The failure to influence adolescent uptake in the general population suggests the need to explore new ways of targeting adolescents before they become addicted to smoking.

Prevention programmes aimed at the young generally use a recall measure of smoking to identify adolescents at risk of becoming dependent smokers. Typically, this measure asks adolescents to recall whether they have smoked in the past 30 days. One problem with this measure is the relatively long recall period, especially for adolescents as young as 12 years of age. A second problem concerns the irregularity of smoking during adolescence. This would cause a measure of the previous month's smoking to miss many adolescents at risk of becoming regular smokers. Some researchers now speculate that the smoking uptake process consists of intermittent bouts of smoking alternating with long periods of no smoking, rather than an orderly build up of consumption levels. ${ }^{4,5}$ Indeed, it is possible that some smokers continue an intermittent pattern of occasional smoking into adulthood. ${ }^{6}$ Lastly, we note that many individuals experiment with cigarettes during adolescence without proceeding further. For these reasons, a measure of smoking in the last month may be a poor indicator of the likelihood of future smoking. A recent population-based study followed adolescents for three years and confirmed that a baseline measure of last month's smoking was a poor predictor of which adolescents were smokers at follow up.?

When prevention is the goal, it may be more appropriate to develop a measure that does not rely on recall of smoking experience to identify adolescents at risk of becoming regular smokers. Most researchers accept that the smoking uptake process consists of a series of identifiable stages. ${ }^{8-11}$ Included in this model is the concept of a preparatory stage preceding experimentation with cigarettes, during which adolescents develop and modify beliefs and attitudes related to smoking. The development of a predisposition to smoke has received 
little research attention. Some investigators focus on adolescents who are contemplating smoking, as indicated by their expressed intentions to smoke. ${ }^{11,12}$ However, the correlation between intention to smoke and future smoking is not high. ${ }^{13,14}$

In this article, we introduce a measure intended to identify adolescents who are in the predisposition stage. We suggest that the predisposition may be better conceptualised as a "susceptibility" to smoking, rather than as a positive intention to smoke. It is not clear that teenagers rationally decide to smoke. At the time of their first cigarette, many teenagers may respond to an offer of a cigarette with the rhetorical "why not?", suggesting that the teenager has not thought consciously about whether she or he wants to be a smoker. Thus the move to smoking may result from the absence of a determined decision not to smoke, rather than from a specific resolve to become a smoker. In order to probe fully the strength of adolescent intentions not to smoke, we used a series of questions to assess susceptibility.

Ideally, a measure of adolescent smoking behaviour should identify a percentage of adolescents at risk of becoming regular smokers that is comparable to the percentage of adolescents who will eventually become adult smokers. Also, such a measure should be related to the same factors that are related to current adolescent smoking. If the susceptibility measure demonstrates these characteristics, it would have sufficient "face" validity to warrant further investigation in future longitudinal studies.

\section{Methods}

The 1992 California Tobacco Survey (CTS) was a random digit dialled survey of 14736 households. An adult in the household supplied basic demographic data and information on smoking status for each household member. Of the 29434 people enumerated, 2299 were between the ages of 12 to 17 years and in-depth interviews were completed for 1789 of these adolescents $(77.8 \%)$. Among those enumerated who were older than 17 years, all reported current smokers and those who had smoked in the past five years were scheduled for the adult in-depth interview. In addition, a random sample of $28 \%$ of all other adults was scheduled for the in-depth interview. Poststratification weighting ensured that the sample was representative of the California population according to 1992 updates to the 1990 census data by age, sex, education, and race/ethnicity. Altogether, 11532 adults were scheduled, of whom $8224(71.3 \%)$ completed the scheduled interview. Of these, 961 were special interviews regarding smoking and pregnancy and 7263 were the complete adult interview. Respondents to the complete adult interview included 1667 people between 18 and 28 years of age.

The 14 minute (average time) adult in-depth interview included a complete recent and lifetime smoking history and questions on current and past use of other tobacco products, health beliefs, social attitudes toward smoking, and tobacco policies. Adults were also asked about smoking restrictions encountered in the workplace, physician advice to stop smoking, non-smoker activism, and exposure to media messages. The teenager in-depth interview averaged about 20 minutes. In addition to personal use of cigarettes and other tobacco products, the teenager interview included questions on peer norms for health behaviours, smoking among family and peers, knowledge of health issues related to smoking, tobacco advertising, and a depression scale.

QUESTIONS USED TO DEFINE TEENAGER SMOKING STATUS ON THE 1992 CTS

Three measures of smoking status were investigated: daily smoking, smoking in the last month, and susceptibility to smoke. We defined these measures as follows: (1) a daily adolescent smoker was defined as anyone who had smoked on 25 or more days in the past month; (2) a current adolescent smoker was defined as anyone who reported smoking one or more cigarettes in the last month (this measure included both daily and non-daily smokers); and (3) an adolescent susceptible to smoking was defined as anyone who did not show a firm resolve not to smoke in the future. The susceptibility measure included both daily smokers and adolescents who had smoked in the last month.

We assessed susceptibility using the questioning procedure outlined in fig 1 . Adolescents who indicated that they had never even puffed on a cigarette were asked whether they thought that they would try a cigarette soon. A positive response to this item was sufficient for that person to be labelled as susceptible to smoking. Adolescents who had puffed on a cigarette were asked whether they would accept a cigarette from a best friend if it were offered. Any response other than "definitely not" was sufficient for that individual to be labelled as susceptible to smoking. Anyone who had smoked a whole cigarette was asked if they thought that they would smoke a cigarette at any time during the next year. Any response other than "definitely not" was sufficient for the individual to be labelled as susceptible to smoking. All those who had puffed on a cigarette but were not classified as susceptible to smoking on the best friend question were queried about whether they would smoke a cigarette at any time in the next year with the same classification decisions applied. Any person who had smoked in the last month was automatically defined as susceptible to smoking.

\section{QUESTIONS USED TO DEFINE ADULT SMOKING} STATUS ON THE 1992 CTS

In order to track the prevalence of daily smoking, smoking in the last month, and susceptibility to smoking into adulthood, we developed comparable categories from the adult survey. Adult never-smokers were asked the questions on trying a cigarette soon and 


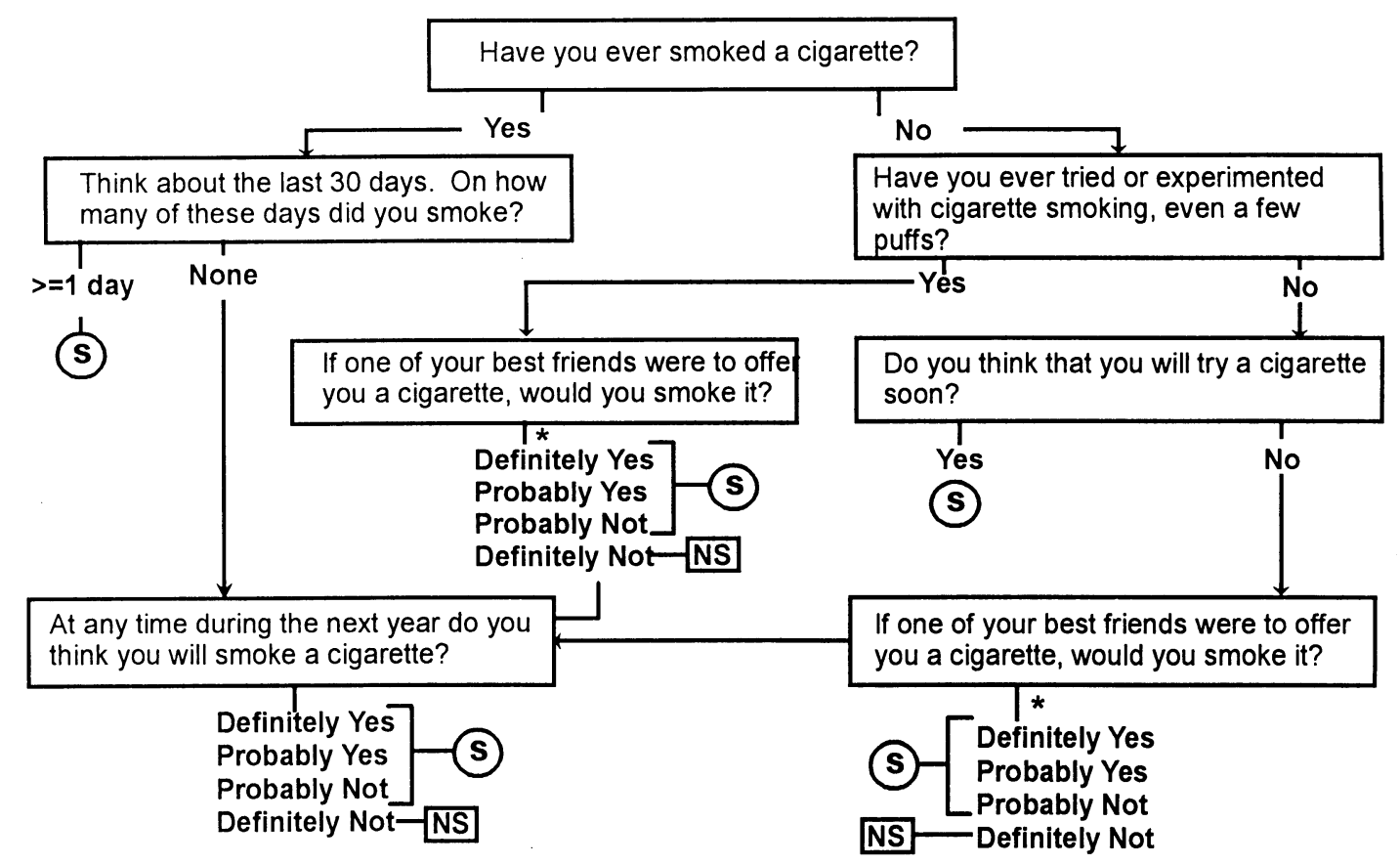

Source: CTS 1992

(S) Susceptible NS Not Susceptible

* Refused/Don't know and missing responses were classified as susceptible

Figure 1 Questions used to define susceptibility in adolescents.

smoking in the next year. Adults who answered yes to the question "Do you smoke cigarettes now?" were also asked on how many days in the last month they had smoked, and categorised as daily smokers if the response was 25 days or more. In addition, all former smokers who had smoked in the past 10 years were asked "Do you think that it is likely or unlikely that you will return to smoking in the next 12 months?" and "Do you think that there is any possible situation in which you might start smoking again?". Former smokers were classified as susceptible to resume their smoking habit unless they indicated that they were unlikely to return to smoking and also indicated that there was no situation in which they might start again.

An experimenter (teenager or adult) was defined as anyone who had ever smoked a whole cigarette, but who had a lifetime total of less than 100 cigarettes.

\section{STATISTICAL ANALYSES}

One method of assessing the face validity of the susceptibility measure is to examine whether variables known to predict current smoking among adolescents are also predictive of adolescent susceptibility to smoking. To this end we undertook logistic regression analyses that adjusted for demographic variables, and evaluated the strength of the relationship of well established predictors of adolescent smoking to each measure. Three separate analyses were performed using: (1) current adolescent smoker as the dependent variable, (2) adolescent susceptible to smoking as the dependent variable, and (3) adolescent susceptible to smoking as the dependent variable, deleting anyone who had smoked a whole cigarette from the analysis. The independent variables used in these analyses and their definitions are described in the appendix. Jackknife procedures were used to derive variance estimates for computing confidence intervals on the risk ratios obtained from the logistic regressions. ${ }^{15,16}$ In addition, a lower $95 \%$ confidence limit is computed for the quantity, $-2 \log$ likelihood, using the jackknife procedure, and a $\mathrm{p}$ value computed to test the hypothesis that all regression coeficients are zero. We performed all analyses using the Statistical Analysis Software (SAS) package. $^{17}$

\section{Results}

MEASURES OF SMOKING BY AGE

The usefulness of categorisations of adolescent smoking behaviour based on susceptibility or on measures of smoking experience was assessed by examining the prevalence of these measures across the life cycle. We hypothesised that the percentage of adolescents classified as susceptible to smoking would more accurately reflect the percentage of individuals who are smokers in adult life than either a measure of adolescent smoking in the past 30 days or a measure of adolescent daily smoking.

Figure 2A presents the measures of daily smoking, smoking in the last month, and susceptibility to smoking by age for the Californian male population. By definition, the curves are cumulative so that the rate of being susceptible to smoking includes those who had smoked in the last month, which in turn includes daily smokers. The prevalence of 


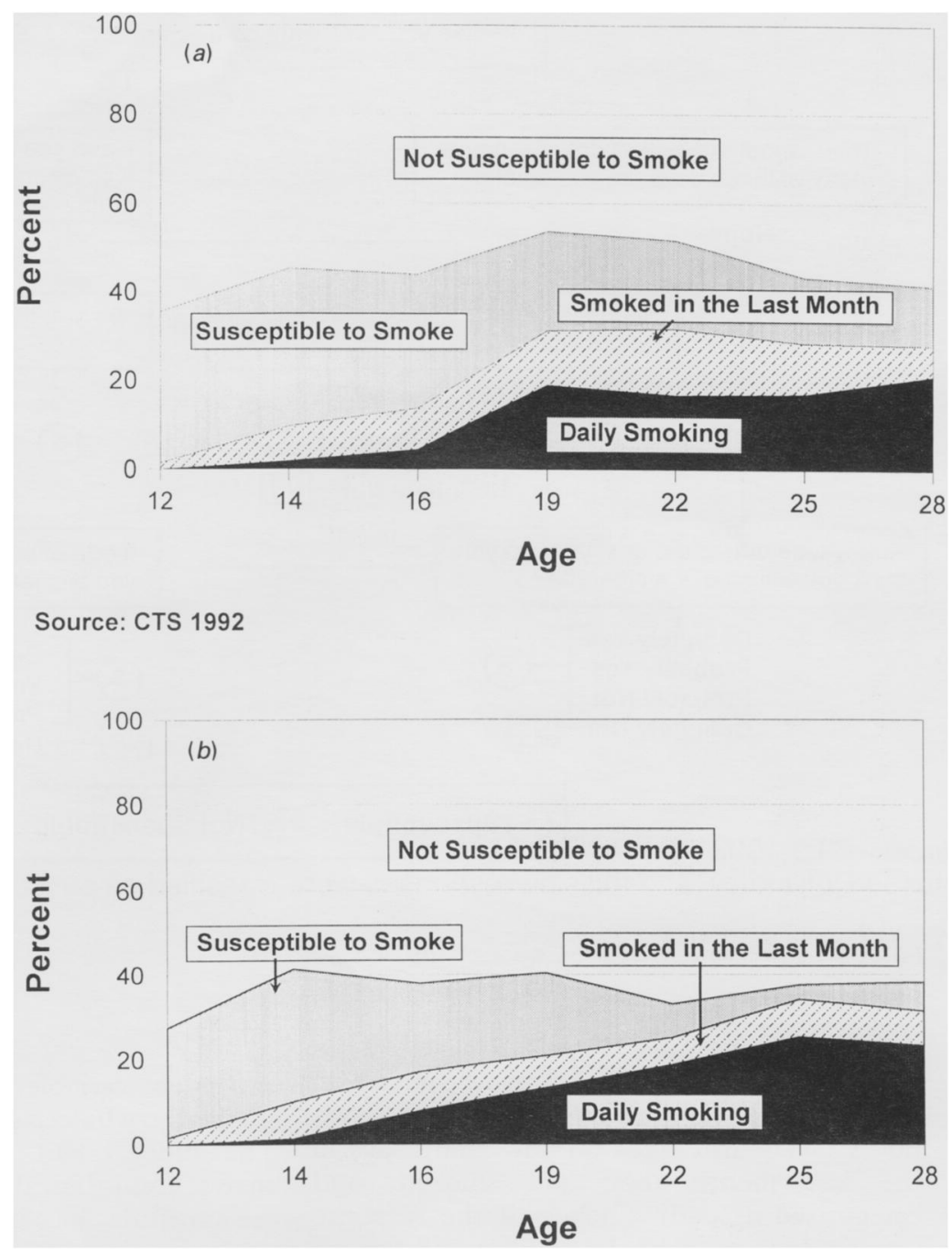

Source: CTS 1992

Figure 2 (A) Measures of smoking behaviour among Californian males. (B) Measures of smoking behaviour among Californian females.

daily smoking among 12 year old boys was zero and only $2 \%$ had used cigarettes in the past month. However, $38 \%$ were classified as susceptible to smoking. Reported smoking in the last month rose to $38 \%$ by 19 years, after which it levelled off. Susceptibility also peaked at over $50 \%$ at 19 years, but in contrast to use in the last month, began to decline after 19 . Although a measure of smoking in the last month (including both daily and non-daily smoking) captured more of the adolescent population than a measure of daily smoking, we still see a major discrepancy between the low numbers of 12-15 year olds who reported smoking in the last month, and the percentage of older age groups who were daily smokers.

The pattern of relationships between daily smoking, last month smoking, and smoking susceptibility across age was somewhat similar for Californian females (fig 2B). About a quarter of 12 and 13 year old girls were classified as susceptible to start smoking, although actual cigarette use was very low. Approximately $40 \%$ of $14-20$ year olds were susceptible to smoking. Susceptibility among females began to decline in the late 20 s, almost a decade later than males. Again, a measure of susceptibility to smoking appears to capture more of the young adolescent population who may eventually become adult smokers than either of the other two measures. In contrast to males, the curves for all three measures peaked at around 25 years.

EXPERIMENTATION AMONG THOSE SUSCEPTIBLE AND NOT SUSCEPTIBLE TO SMOKING BY AGE Approximately $14 \%$ of 12 year olds who were susceptible to smoking reported having smoked a whole cigarette (fig 3A). This proportion increased dramatically through the teenage years such that by 19 years $90 \%$ of those who were susceptible to smoking had already experimented with cigarettes. Note that by adulthood, all those susceptible were current smokers, or quitters who could not rule out a relapse.

Figure 3B shows the experimentation history of those who were classified as not susceptible to smoking. As this figure shows, a large proportion of the population had experimented with cigarettes but were not suscep- 

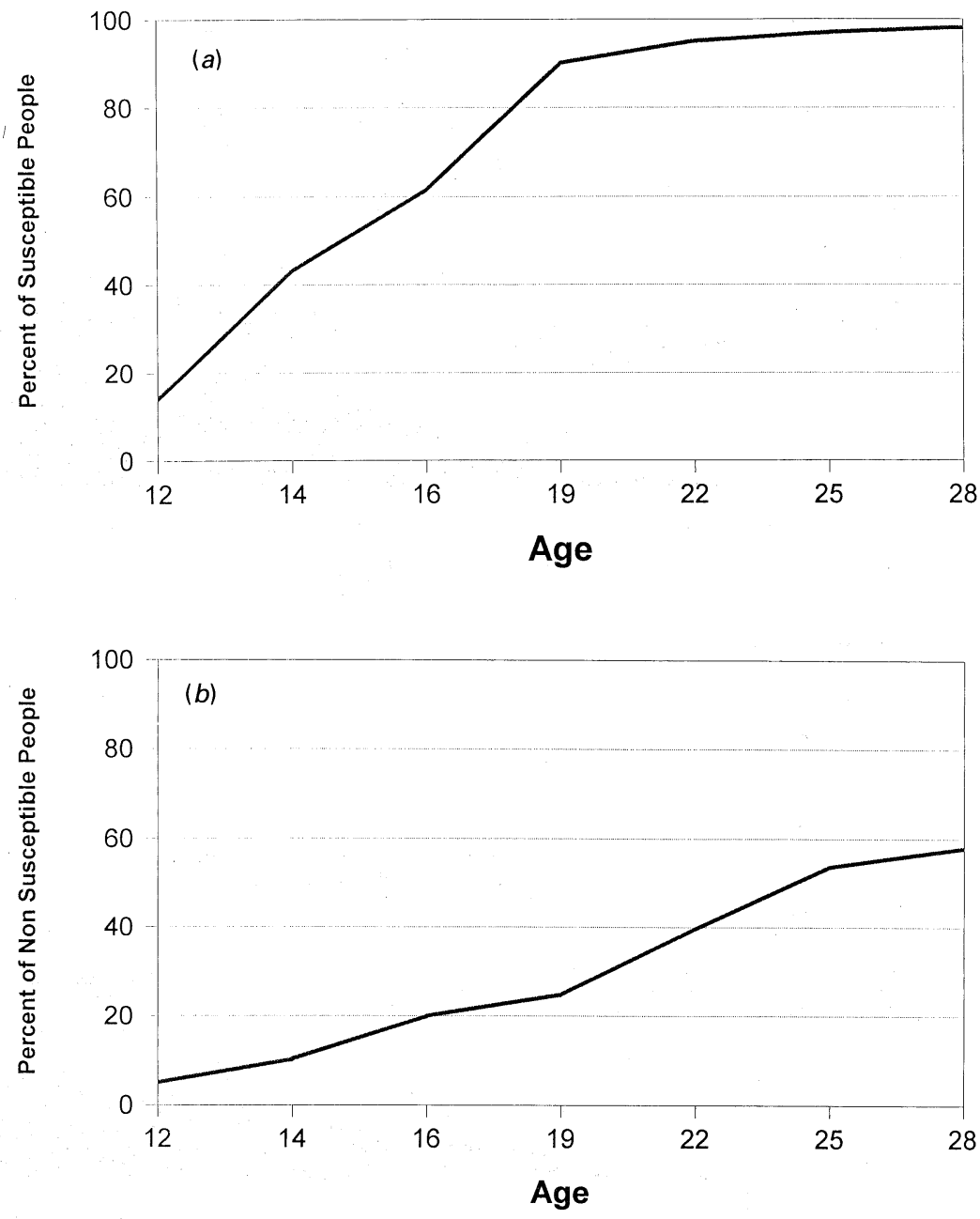

Source: CTS 1992

Figure 3 (A) Experimentation among those susceptible to smoking, by age. (B) Experimentation among those not susceptible to smoking, by age.

tible to smoking again at the time of survey. Even among 12 year olds, approximately $5 \%$ had smoked a whole cigarette but were currently certain that they would not smoke again. This proportion increased up to 25 years of age, by which time over $50 \%$ of those who were no longer susceptible to smoking had smoked a whole cigarette. It should be recalled that adults susceptible to smoking are former smokers who are vulnerable to relapse.

FACTORS RELATED TO CURRENT SMOKING AND SUSCEPTIBILITY TO SMOKING IN ADOLESCENTS To determine whether the susceptibility to smoke measure appears to identifiy adolescents who have the same characterisitics as those who become current smokers, we conducted three logistic regression analyses. The appendix gives a detailed description of the factors analysed. Table 1 presents odds ratios with $95 \%$ confidence intervals for three logistic regression analyses of the likelihood that an adolescent was (1) a current smoker, (2) susceptible to smoking in the future (includes current smokers), and (3) susceptible to smoking in the future among those who have never smoked a whole cigarette. For most variables, the odds ratios are fairly consistent regardless of which dependent variable is analysed. Also, eliminating those adolescents who had smoked a whole cigarette only slightly changes the magnitude of the odds ratios compared to all those susceptible to smoking. Four variables that predict current smoking appear to be less closely associated with susceptibility to smoking: a health belief (perception of no harm in experimentation), school performance, depression, and in particular, exposure to peer smokers. However, the tendency for these factors to be related to susceptibility is still present or suggested.

\section{Discussion}

By the age of 12 to 13 years, approximately $2 \%$ of Californian adolescents had smoked in the last month and none were daily smokers. At 17 years, $10 \%$ of adolescents were daily smokers and $13 \%$ reported smoking in the last month. By the end of adolescence, approximately $31 \%$ of 19 year olds had smoked in the last month and $20 \%$ were daily smokers. The relatively high proportion of the oldest adolescents who are already smoking daily highlights the importance of reaching adolescents at a young 
Table 1 Factors related to current adolescent smoking and susceptibility to smoking. Values are odds ratios (95\% confidence intervals).

\begin{tabular}{|c|c|c|c|c|}
\hline \multirow[b]{2}{*}{ Measure } & \multirow[b]{2}{*}{ Subgroup } & \multicolumn{3}{|c|}{ Smoking status } \\
\hline & & $\begin{array}{l}\text { Current smokers } \\
\quad(n=1789)\end{array}$ & $\begin{array}{c}\text { Susceptible } \\
\text { to smoking }(n=1789)\end{array}$ & $\begin{array}{l}\text { Susceptible among those } \\
\text { never smoking a whole } \\
\text { cigarette }(n=1309)\end{array}$ \\
\hline $\begin{array}{l}\text { Personal influence } \\
\text { Number of perceived } \\
\text { benefits to smoking }\end{array}$ & $\begin{array}{l}\text { None } \\
\text { One } \\
\text { Two or three } \\
\text { Four or more }\end{array}$ & $\begin{array}{l}1.3(0.5-3.2) \\
2.6(1.2-5.5) \\
1.8(0.7-4.4)\end{array}$ & $\begin{array}{l}1.6(1.1-2.4) \\
2.0(1.4-3.0) \\
2.0(1.2-3.5)\end{array}$ & $\begin{array}{l}1.6(1.0-2.4) \\
2.1(1.3-3.4) \\
2.2(1.1-4.3)\end{array}$ \\
\hline $\begin{array}{l}\text { Harm of } \\
\text { experimentation }\end{array}$ & $\begin{array}{l}\text { Some } \\
\text { None }\end{array}$ & $3.7(2 . \overline{-}-6.0)$ & $2.6(\overline{1.9}-3.7)$ & $2.3(\overline{1.7}-3.2)$ \\
\hline School performance & $\begin{array}{l}\text { Better than average } \\
\text { Average or below }\end{array}$ & $1.9(1 . \overline{1-3.4})$ & $1.3(\overline{1.0}-1.7)$ & $1.1(0.9-1.5)$ \\
\hline Liking for school & $\begin{array}{l}\text { A lot } \\
\text { Some, little, not at all }\end{array}$ & $1.6\left(1.0^{-}-2.7\right)$ & $1.4(\overline{1.1}-2.0)$ & $1.5(\overline{1.0}-2.0)$ \\
\hline Depression & $\begin{array}{l}\text { Below median } \\
\text { Above median }\end{array}$ & $1.9(1 . \overline{1-3.3})$ & $1.2(\overline{0.8-1.7)}$ & $1.3(\overline{0.9-1.8)}$ \\
\hline Rebelliousness & $\begin{array}{l}\text { None } \\
\text { Some }\end{array}$ & $1.4(0 . \overline{-}-3.6)$ & $1.4(\overline{1.0}-2.0)$ & $1.5(\overline{1.0}-2.2)$ \\
\hline $\begin{array}{l}\text { Environmental influ } \\
\text { Exposure to } \\
\text { peer smokers }\end{array}$ & $\begin{array}{l}\text { easures } \\
\text { None } \\
\text { Some } \\
\text { Best friends of one sex } \\
\text { Best friends of both sexes }\end{array}$ & $\begin{array}{c}- \\
1.0(0.5-2.3) \\
7.5(3.4-15.9) \\
21.0(9.7-45.3)\end{array}$ & $\begin{array}{l}- \\
1.1(0.7-1.8) \\
2.4(1.5-3.8) \\
4.8(2.8-8.5)\end{array}$ & $\begin{array}{l}1.1(0.7-1.8) \\
1.9(1.1-3.3) \\
2.1(0.9-4.8)\end{array}$ \\
\hline $\begin{array}{l}\text { Exposure to } \\
\text { familial smokers }\end{array}$ & $\begin{array}{l}\text { None } \\
\text { Some }\end{array}$ & $1.3(0.6-2.6)$ & $1.3(\overline{1.0}-1.8)$ & $1.2(0 . \overline{9}-1.7)$ \\
\hline $\begin{array}{l}\text { Pro-smoking norms } \\
\text { among peers and/or } \\
\text { family }\end{array}$ & $\begin{array}{l}\text { None } \\
\text { One } \\
\text { Two or more }\end{array}$ & $\begin{array}{l}-\overline{-} \\
1.4(0.7-2.8) \\
2.5(1.2-4.9)\end{array}$ & $\begin{array}{l}1.0(0.8-1.5) \\
1.9(1.3-2.8)\end{array}$ & $\begin{array}{l}1.0(0.7-1.3) \\
2.3(1.4-3.9)\end{array}$ \\
\hline
\end{tabular}

Odds ratios are adjusted for age, gender, and race/ethnicity as well as other factors shown in the table. Lower $95 \%$ CI for -2 log likelihood is $269.1,289.6$, and 133.8 for analyses of current smokers, susceptible to smoking, and susceptible to smoking among those never smoking a whole cigarette, respectively. All analyses are statistically significant, $\mathrm{p}<0.0001$

age, before they establish a cigarette dependency. However, to reach young adolescents early on in the uptake process we need measures that will be a better reflection of the proportion of adolescents who become smokers at older ages. At 12 to 13 years, the prevalence of last month or daily smoking is minimal. Thus using these measures to target young adolescents for prevention programmes runs the risk of missing many, if not most, of those at risk of smoking at later ages.

Our measure of susceptibility classified $27 \%$ of 12 to 13 year olds as susceptible to smoking another cigarette or their first cigarette. Although susceptibility to smoke overestimates the percentage of adolescents who will become adult daily smokers (not everyone classified as susceptible will become a daily smoker), this measure seems better positioned to include those adolescents at risk for daily smoking in later life than either of the two conventional measures of adolescent smoking behaviour.

Additional support for the validity of this measure is the finding that most factors known to be related to adolescent smoking also appear to be related to susceptibility to smoke (table 1). Because susceptibility is a more inclusive measure, we expected that these factors would be slightly less predictive. Exposure to peer smokers was considerably more predictive of current smoking than of susceptibility to smoking, perhaps because adolescents tend to smoke in the company of their smoking friends. Smoking adolescents might also be more likely to deny that smoking is harmful in order to rationalise their behaviour. Depression appears to be more related to current smoking than susceptibility to smoking; it may serve as a trigger to initiate smoking among those who are susceptible to smoking. The analyses presented in this study were also performed on data collected in the 1990 CTS with entirely consistent results. ${ }^{18}$ Because most predictors of current smoking are also independent predictors of susceptibility and because these results were also highly reproducible, the susceptibility measure would appear to have considerable face validity.

The definitive validation of the susceptibility measure as a predictor of future smoking behaviour will need to take place within the setting of a longitudinal study. Adolescents not currently smoking at the initial interview will be classified as susceptible or not susceptible to smoking and then followed up several years later to determine whether or not they have smoked in the interim or are current smokers at the time of follow up. If susceptibility is a predictor of future smoking, a much higher percentage of those susceptible to smoking will have experimented or reached the status of current smoker at follow up than those not susceptible to smoking. It would also be interesting to determine whether a past history of experimentation is related to smoking at follow up independently of the susceptibility measure.

The data in fig 2 indicate that a higher percentage of people are susceptible to smoking than actually smoke. Thus we would expect that many susceptible adolescents will not progress to current smoking and eventual daily smoking. Conversely, a firm determination not to smoke at the time of the initial interview may dissolve later, especially if an adolescent makes new friends who are smokers. Thus we cannot expect prediction to be perfect. Nevertheless, the results of a longitudinal study will 
determine the validity and potential usefulness of the susceptibility measure.

The susceptibility measure includes both experimenters and never-smokers. Conventionally antismoking interventions focus on preventing experimentation with cigarettes. Yet, as is well documented, ${ }^{19,20}$ the majority of teenagers try a cigarette, but only a fraction of these proceed to develop a smoking habit. Consistent with this research, we found that $70 \%$ of Californian teenagers classified as not susceptible to smoking had previously at least puffed on a cigarette. Some adolescents perhaps smoke a cigarette just for the experience. Consequently, a focus on preventing experimentation may not be the best way to reduce smoking prevalence among adolescents. It may be more important to dissuade teenagers from smoking another cigarette, whether or not they have already tried a cigarette, because after experimentation teenagers are apparently still open to the suggestion that they never smoke again.

The concept of susceptibility is designed to identify those adolescents who are not adamant that they will never smoke. Included in the group of those susceptible to smoking are adolescents who cannot rule out the possibility of trying a cigarette soon, of smoking in the next year, or of accepting a cigarette from a best friend. The latter item reflects the importance of close peers during adolescence as role models and as sources of normative pressure..$^{8,10,21,22}$ Although a conscious intention to become a smoker may be present in some of the teenagers classified as susceptible, it was not present in everyone. Only $28 \%$ of those susceptible to smoking answered "probably yes" or "definitely yes" to the question about whether they would smoke a cigarette in the next year; another $57 \%$ answered "probably not". Here, Goddard's recent study is again suggestive. ${ }^{7}$ The study followed a sample of 4334 British children (aged 11 to 15 years) for four years, with over 4000 children surveyed annually. The proportion of teenagers who said they wanted to become a smoker was considerably lower than either the proportion of teenagers who thought they would be smokers or the proportion who were actually categorised as smokers in later survey years.

A measure of susceptibility appears to be a promising means of identifying teenagers who need help in establishing cognitive barriers to future smoking. Unlike the recall measures that are conventionally used, susceptibility is a current status measure and is thus likely to provide a more stable assessment of status, thereby increasing confidence in our ability to monitor trends among adolescents. Subject to further validation in longitudinal studies, we propose a measure of susceptibility as a tool for surveillance and as a means of refocusing prevention efforts to reach adolescents before they become addicted to smoking.

This study was supported by Contract No 89-97872 from the California Department of Health Services, Tobacco Control Section, Sacramento.

\section{Appendix}

Numerous investigations of teenage smoking behaviour over the past 30 years have produced a wide array of factors thought to influence teenagers to start smoking. For the purpose of this study, we classified these factors as personal influences, which relate directly to the individual's perceptions and state of mind, and environmental influences, which relate to external factors such as who the individual associates with and what they believe. This appendix gives a brief rationale for including each factor, describes how it was coded from the CTS data, and presents the distribution of the population with respect to each variable and demographic characteristics (table 2).

\section{PERSONAL INFLUENCES}

\section{Perceived benefits of smoking}

Various studies of adolescents have related presumed benefits of smoking to smoking uptake. ${ }^{23-28}$ Five Yes-No questions from the CTS addressed the perceived benefits of smoking. These were:

(1) Do you believe smoking can help people when the are bored?

(2) Do you believe cigarette smoking helps people relax?

(3) Do you believe cigarette smoking helps reduce stress?

(4) Do you believe smoking helps people feel more comfortable at parties and in other social situations?

(5) Do you believe smoking helps people keep their weight down?

The number of Yes responses was categorised as none, one, two, three, and four or more for analysis.

\section{Harm of experimentation}

Most health education programmes endeavour to inform children about the dangers of tobacco use, including experimentation. The CTS included three questions that addressed whether adolescents are aware of these dangers.

(1) Do you believe it's safe to smoke for only a year or two?

(2) Do you believe there is any harm in having an occasional cigarette?

(3) If I started to smoke regularly, I could stop smoking any time I wanted.

Yes, No, or No Opinion responses were elicited. An additive index was computed based on the number of responses indicating the perception that experimentation is safe.

\section{School performance}

Previous studies have shown that adolescents who feel that they are performing inadequately at school are more likely to turn to smoking. ${ }^{29}$ Lack of success in conventional roles may encourage adolescents to find smoking more attractive, perhaps as a behaviour signalling deliberate non-conformity. ${ }^{30}$ The CTS asked adolescents to rate their performance in school as very much above average, above average, 
Table 2 Distribution of factors analysed with respect to smoking status and susceptibility to smoking

\begin{tabular}{|c|c|c|}
\hline Factors & & Weighted percentage \\
\hline $\begin{array}{l}\text { Demographics } \\
\text { Age }\end{array}$ & $\begin{array}{l}12 \\
13 \\
14 \\
15 \\
16 \\
17\end{array}$ & $\begin{array}{l}19 \\
15 \\
18 \\
16 \\
18 \\
14\end{array}$ \\
\hline Sex & $\begin{array}{l}\text { Male } \\
\text { Female }\end{array}$ & $\begin{array}{l}50 \\
50\end{array}$ \\
\hline Race & $\begin{array}{l}\text { Non-Hispanic white } \\
\text { Black } \\
\text { Hispanic } \\
\text { Asian }\end{array}$ & $\begin{array}{r}47 \\
9 \\
34 \\
10\end{array}$ \\
\hline $\begin{array}{l}\text { Personal influence } \\
\text { Number of perceived } \\
\text { benefits to smoking }\end{array}$ & $\begin{array}{l}\text { None } \\
\text { One } \\
\text { Two or three } \\
\text { Four or more }\end{array}$ & $\begin{array}{l}35 \\
23 \\
30 \\
12\end{array}$ \\
\hline $\begin{array}{l}\text { Harm of } \\
\text { experimentation }\end{array}$ & $\begin{array}{l}\text { Some } \\
\text { None }\end{array}$ & $\begin{array}{l}55 \\
45\end{array}$ \\
\hline School performance & $\begin{array}{l}\text { Better than average } \\
\text { Average or below }\end{array}$ & $\begin{array}{l}54 \\
46\end{array}$ \\
\hline Liking for school & $\begin{array}{l}\text { A lot } \\
\text { Some, little, not at all }\end{array}$ & $\begin{array}{l}36 \\
64\end{array}$ \\
\hline Depression & $\begin{array}{l}\text { Below median } \\
\text { Above median }\end{array}$ & $\begin{array}{l}50 \\
50\end{array}$ \\
\hline Rebelliousness & $\begin{array}{l}\text { None } \\
\text { Some }\end{array}$ & $\begin{array}{l}20 \\
80\end{array}$ \\
\hline $\begin{array}{l}\text { Environmental influ } \\
\text { Exposure to } \\
\text { peer smokers }\end{array}$ & $\begin{array}{l}\text { None } \\
\text { Some } \\
\text { Best friends of one sex } \\
\text { Best friends of both sexes }\end{array}$ & $\begin{array}{l}19 \\
40 \\
26 \\
15\end{array}$ \\
\hline $\begin{array}{l}\text { Exposure to } \\
\text { familial smokers }\end{array}$ & $\begin{array}{l}\text { None } \\
\text { Some }\end{array}$ & $\begin{array}{l}27 \\
73\end{array}$ \\
\hline $\begin{array}{l}\text { Pro-smoking norms } \\
\text { among peer and/or } \\
\text { family }\end{array}$ & $\begin{array}{l}\text { None } \\
\text { One } \\
\text { Two or more }\end{array}$ & $\begin{array}{l}28 \\
53 \\
19\end{array}$ \\
\hline
\end{tabular}

average, or below average. For our analyses, we grouped the above average responses and the average and below responses.

\section{Liking for school}

Although liking for school is related to school performance, preliminary analyses found a significant number of adolescents who do poorly but like school, or who do well but do not like school. The anxiety caused by poor grades may be counterbalanced by other elements of the school experience that afford a positive attitude toward school life. CTS respondents were asked whether they liked school a lot, some, a little, or not at all. Those liking school a lot were contrasted with all others.

\section{Depression}

Adolescents who are depressed have been shown to be more likely to smoke than those who are not depressed. ${ }^{27,31}$ The CTS used a series of six questions that have previously been scaled and found to be valid and reliable for use among adolescents. ${ }^{32}$

(1) During the past 12 months, how often have you felt too tired to do things?

(2) During the past 12 months, how often have you had trouble going to sleep or staying asleep?

(3) During the past 12 months, how often have you felt unhappy, sad, or depressed?
(4) During the past 12 months, how often have you felt hopeless about the future?

(5) During the past 12 months, how often have you felt nervous or tense?

(6) During the past 12 months, how often have you worried too much about things?

Each item had four choices for response: Often, Sometimes, Rarely, or Never. With Never counted as zero, Rarely as one, and so forth, the items were added to form a scale score for each individual. The median of the scale score was used to divide the sample into two groups.

\section{Rebelliousness}

Being rebellious or engaging in risk taking behaviours has been related to smoking among adolescents. ${ }^{27}$ Seven items from the CTS were used to assess these attitudes.

(1) I get a kick out of doing things every now and then that are a little risky or dangerous.

(2) During the past year, have you been in a physical fight that involved hitting, pushing, shoving, or any other kind of physical contact? (Do not include family fights, such as fights with brothers and sisters)

(3) My family looks for things to nag me about.

(4) I have a lot of arguments with my family.

(5) If anyone upsets me I usually try to get revenge.

(6) I don't mind getting into trouble telling lies if it helps my friends. 
(7) I don't mind lying to keep my friends out of trouble with the authorities.

Responses were Agree or Disagree. The reliability index of a scale with Disagree scored as 0 and Agree as 1 was 0.66 (Cronbach's $\alpha$ ). For the present study, we contrasted anyone with a response of Agree to any item with those who disagreed with all the statements.

\section{EXTERNAL OR ENVIRONMENTAL INFLUENCES Exposure to peer smokers}

The opportunity to observe others perform a behaviour and to see the consequences that follow is a powerful determinant of the expectations formed by the individual for selfperformance of that behaviour. One of the strongest and most consistent findings in the smoking initiation literature is that teenagers who are exposed to smokers in the family or among peers are more likely to smoke themselves than teenagers who are unexposed. ${ }^{33-36}$ The CTS asked adolescents to indicate the number of their best male and best female friends who smoked. This was followed by two questions on acquaintances, in which one response category to the second question was "don't have friends who smoke":

(1) How many people do you know who are about your age who smoke cigarettes?

(2) Do any of your friends who smoke say that they should quit smoking?

From these questions, four subgroups were determined: if the number of best male and best female friends and those they know who are about the same age is zero and if they responded "don't have friends who smoke" to the last item, adolescents were categorised as minimally exposed to peers who smoke. Respondents giving a number for best male or best female friends were categorised as having best friends of one or of both sexes who smoke. The remainder were considered as having friends or acquaintances who smoke.

\section{Exposure to familial smokers}

Having parents who smoke not only allows for behavioral observation as described above, but may lead the adolescent to perceive lack of parental disapproval for smoking. Adolescents were asked whether any member of their household smoked, and whether they had any relatives outside the household who smoked. Those with smokers in their families were contrasted to those without.

\section{Familial and peer norms regarding smoking}

The normative codes of conduct are established particularly strongly by the family and peer networks. Adolescence has been established as a period in which individuals begin to favour the norms of their peers over the norms of their parents, although parental norms may remain important for some behaviours. ${ }^{37-39}$ Three sets of norms were measured by the CTS, parental norms, general peer norms, and norms of adolescents' best friends, using the following five items.
(1) When I'm older my parents won't mind if I smoke. (Yes/No)

(2) If you lit up a cigarette tomorrow in front of your parents, how do you think that they would react? (Yes/No)

(3) Do you think people your age care about staying off cigarettes? (Yes/No)

(4) How do you think that your best friends would feel about you smoking one or more packs of cigarettes a day? (Approve/ Disapprove)

(5) How do you think that your best friends would feel if you used chewing tobacco and snuff regularly? (Approve/ Disapprove)

Yes or Approve responses were counted as 1, and No or Disapprove responses as 0 , and added together. Categories were formed for zero, one, and two or more norms supportive of smoking.

Supported by contract No 89-97872 from the California Department of Health Servies, Tobacco Control Section, Sacramento.

1 Gilpin EA, Lee L, Pierce JP. Smoking initiation rates in adults and minors. United States 1944-1988. Am f Epidemiol 1994; 140: 535-43.

2 Pierce JP, Fiore MC, Novotny TE, Hatziandreu EJ, Davis RM. Trends in cigarette smoking in the United States: projections to the year $2000 . \mathcal{F} A M A 1989 ; 261: 61-5$.

3 Projections to the year 2000 . GAlpin E. Trends in physicians' smoking behavior and patterns in advice to quit. In: Tobacco and the clinician. Interventions for medical and dental practice. Monograph 5. Bethesda, MD: National Institutes of Health, National Cancer Institute, 1994: 12-23. (NIH Publication No 94-3693.)

4 Chassin LA, Presson CC, Sherman SJ. Stepping backward in order to step forward: an acquisition-oriented approach to primary prevention. $\mathcal{f}$ Consult Clin Psychol 1985; 53: 612-22.

5 Hirschman RS, Leventhal H, Glynn K. The development of smoking behavior: conceptualization and supportive cross-sectional survey data. $\mathcal{F}$ Appl Soc Psychol 1984; 14: cross-section.

6 Evans NJ, Gilpin E, Pierce JP, Burns DM, Borland R, Johnson $\mathrm{M}$, et al. Occasional smoking among adults evidence from the California Tobacco Survey. Tobacco Control 1992; 1: 169-75.

7 Goddard E. Why children start smoking: an enquiry carried out by social survey division of OPCS on behalf of the Department of Health. London: HMSO, Office of Population Censuses and Surveys, Social Survey Division, 1990.

8 Best JA, Thompson SJ, Santi S, Smith EA, Brown KS. Preventing cigarette smoking among school children. Annu Rev Public Health. 1984; 14: 257-73.

9 Chassin LA, Presson CC, Sherman SJ, Edwards DA. The natural history of cigarette smoking: predicting youngnatural history of cigarette smoking: predicting youngadult smoking outcomes from adolesc
patterns. Health Psychol 1990; 9: 701-16.

10 Flay BR, d'Avernas JR, Best JA, Kersell MW, Ryan K. Cigarette smoking: why young people do it and ways of preventing it. In: McGrath PJ, Firestone P, eds. Pediatric and adolescent behavioral medicine: issues in treatment Springer series on behavior therapy and behaviora medicine, Vol 10. New York: Springer, 1983: 132-83.

11 Stern RA, Prochaska JO, Velicer WF, Elder JP. Stages of adolescent cigarette smoking acquisition: measurement and sample profiles. Addict Behav 1987; 12: 319-29.

12 Elder JP, De Moor C, Young RL, Wildey MB, Molgaard $\mathrm{CA}$, Goldbeck AL, et al. Stages of adolescent tobacco-use acquisition. Addict Behav 1990; 15: 449-54.

13 Best JA, Flay BR, Towson SMJ, Ryan KB, Perry CL, Brown KS, et al. Smoking prevention and the concept of risk. $f$ Appl Soc Psych 1984; 9: 161-201.

14 Chassin L, Corty E, Presson CC, Olshavsky RW Bensanberg M, Sherman SJ. Predicting adolescents intentions to smoke cigarettes. F Health Soc Behav 1981 22: 445-55.

15 Efron B. The jackknife, the bootstrap and other resamplin plans. CBMS Regional Conference Series in Applied Mathematics, 38. Philadelphia: Society for Industria and Applied Mathematics, 1982.

16 Pierce JP, Cavin SW, Macky C, Rosbrook B, Berry CC Maklan DM, et al. Technical report on analytic method: and approaches used in the 1992 California Tobacco Surves analysis. Sacramento, CA: California Department o: analysis. Sacramento,

17 SAS Institute Inc. SAS/STAT user's guide. [Compute program manual] Version 6, 4th ed, vol 2). Cary, NC SAS Institute Inc, 1989. 
18 Pierce JP, Farkas A, Evans N, Berry C, Choi W, Rosbrook $\mathrm{B}$, et al. Tobacco use in California 1992. A focus on preventing uptake in adolescents. Sacramento: CA California Department of Health Services, 1993.

19 Cartwright A, Martin FM, Thompson JG. Distribution and development of smoking habits. Lancet 1959; 31 $725-7$.

20 Salber EJ, Freeman HE, Abelin T. Needed research on smoking: lessons from the Newton study. In: Borgatta EF, Evans RR, eds. Smoking health and behavior. Chicago: Aldine, 1968 .

21 Bauman KE, Fisher LA, Bryan ES, Chenoweth RL. Antecedents, subjective expected utility, and behavior: panel study of adolescent cigarette smoking. Addict Behav $1984 ; 9: 121-36$

22 Leventhal H, Cleary PD. The smoking problem: a review of research and theory in behavioral risk modification Psychol Bull 1980; 88: 370-405.

23 Aitken PP, Leathar DS, O'Hagan FJ, Squair SI. Children's awareness of cigarette advertisements and brand imagery. $\mathrm{Br} \mathcal{F}$ Addict 1987; 82: 615-22.

24 Alexander HM, Callcott R, Dobson AJ, Hardes GR, Lloyd DM, O'Connell DL, et al. Cigarette smoking and drug use in schoolchildren. IV. Factors associated with changes in smoking behaviour. Int $\mathcal{F}$ Epidemiol 1983; 12: 59-66.

25 Charlton A. Smoking and weight control in teenagers. Public Health 1984; 98: 277-81.

26 Goldstein AO, Fisher PM, Richards JW, Cretin D Relationship between high school student smoking and recognition of cigarette advertisements. $\mathcal{F}$ Pediatr 1987 110: 488-91.

27 McAlister AL, Krosnick JA, Milburn MA. Causes of adolescent cigarette smoking: tests of a structural equation model. Soc Psychol $Q$ 1984; 47: 24-36.

28 Perry CL, Murray DM, Klepp KI. Predictors of adolescent smoking and implications for prevention. Morbidity Mortality Weekly Rep 1987; 36(suppl 4):41-5s.

29 US Department of Health and Human Services. Reducing the health consequences of smoking: 25 years of progress. $A$ report of the surgeon general. Rockville, MD: Public Health Service, Centers for Disease Control, 1989. (DHHS Publication No (CDC) 89-8411.)

30 Creswell WH, Huffman WJ, Stone DB. Youth smoking behavior characteristics and their educational implications. A report of the University of Illinois anti-smoking education study. Champaign: University of Illinois, 1970.

31 Mittelmark MB, Murray DM, Luepker RV, Pechacek TF Pirie PL, Pallonen UE. Predicting experimentation with cigarettes: the childhood antecedents of smoking study (CASS). Am $\mathcal{F}$ Public Health 1987; 77: 206-8.

32 Kandel DB, Davies M. Adult sequelae of adolescent depressive symptoms. Arch Gen Psychiatry 1986; 43 255-62.

33 Biddle BJ, Bank BJ, Marlin MM. Parental and pee influences on adolescents. Soc Forces 1980; 8: 1057-79.

34 Chassin LA, Presson CC, Sherman SJ, Montello D, McGrew J. Changes in peer and parent influence during adolescence: longitudinal versus cross-sectional perspectives on smoking initiation. Dev Psychol 1986; 22 327-34.

35 Hundleby JD, Mercer GW. Family and friends as social environments and their relationship to young adolescents' use of alcohol, tobacco, and marijuana. $f$ Marriage Family 1987; 49: 151-64.

36 Kandel DB, Andrews K. Processes of adolescent socialization by parents and peers. Int $\mathcal{F}$ Addict 1987; 22 : $319-43$.

37 Berndt TJ. Developmental changes in conformity to peer and parents. Dev Psychol 1979; 15: 608-16.

38 Brown BB, Clasen DR, Eicher SA. Perceptions of pee pressure, peer conformity dispositions, and self-reported behavior among adolescents. Dev Psychol 1986; 22 . 521-30.

39 Lau RR, Quadrel MJ, Hartman KA. Development and change of young adults' preventive health beliefs and behavior: Influence from parents and peers. $\mathcal{F}$ Health Soc Behav 1990; 31: 240-59. 